\title{
Cyclic Stress Response Behavior of Near $\beta$ Titanium Alloy and Deformation Mechanism Associated with Precipitated Phase
}

\author{
Siqian Zhang ${ }^{1}$, Haoyu Zhang ${ }^{1, *(1)}$, Junhong Hao ${ }^{1}$, Jing Liu ${ }^{1}$, Jie Sun ${ }^{2} \mathbb{D}$ and Lijia Chen ${ }^{1}$ \\ 1 School of Materials Science and Engineering, Shenyang University of Technology, Shenyang 110870, China; \\ sqzhang@alum.imr.ac.cn (S.Z.); wangronnie2016@163.com (J.H.); zwtsysmm@163.com (J.L.); \\ chenlijia@sut.edu.cn (L.C.) \\ 2 State Key Laboratory of Rolling and Automation, Northeastern University, Shenyang 110004, China; \\ sunjie@ral.neu.edu.cn \\ * Correspondence: zhanghaoyu@sut.edu.cn; Tel.: +86-186-2408-7566
}

Received: 25 September 2020; Accepted: 4 November 2020; Published: 6 November 2020

\begin{abstract}
The cyclic stress response behavior of Ti-3Al-8V-6Cr-4Mo-4Zr alloy with three different microstructures has been systematically studied. The cyclic stress response was highly related to the applied strain amplitude and precipitated phase. At low strain amplitude, the plastic deformation was mainly restricted to soft $\alpha$ phase, and a significant cyclic saturation stage was shown until fracture for all three alloys. At high strain amplitude, three alloys all displayed an initial striking cyclic softening. However, the softening mechanism was obviously difference. Interestingly, a significant cyclic saturation stage was noticed after an initial cyclic softening for alloy aging for $12 \mathrm{~h}$, which could be attributed to the deformation of $\{332\}<113>$ twin and precipitation of $\alpha$ " martensite.
\end{abstract}

Keywords: cyclic stress response; cyclic softening; cyclic saturation; $\{332\}<113>$ twinning; stress induced $\alpha^{\prime \prime}$ martensite

\section{Introduction}

Near $\beta$ titanium alloys are extensively used in industry due to their high specific strength, adequate ductility, fracture toughness, biocompatibility and excellent corrosion resistance [1-3]. It is generally known that low cycle fatigue behavior is of utmost importance in the selection of engineering materials, and cyclic stress-strain data have been connected with fatigue crack initiation and fatigue crack propagation rate [4-7]. Therefore, in order to ensure engineering applications, the cyclic stress response behavior must be comprehensively characterized.

As titanium alloys are cyclically strained during fatigue, the response stresses generally show an increase or a decrease as the number of cycles increases, which is termed cyclic hardening or cyclic softening, respectively. In practical applications, the cyclic stress response behavior of titanium alloys tends to be remarkably complex, which is highly dependent on the test temperature, applied plastic strain amplitude, strain rate, microstructure and so on [8-11]. For example, it may display an initial cyclic hardening, then an obvious softening, and finally a saturation stage is reached. Or, an obvious cyclic saturation stage is noticed after an initial cyclic softening until fracture.

Generally speaking, the cyclic stress response behavior is influenced by the competitive effect of the back stress and friction stress during fatigue deformation, which is closely related to dislocation motion [12]. For two phase titanium alloys, the softening behavior is due to a decrease in the kinematic component of stress at room temperature. It is controlled by dislocation configuration in the $\alpha$ phase changing from the heterogeneous distribution to the gradual homogenization [13]. On the contrary, at high temperature, the observed cyclic softening behavior is related to the second phase shearing 
process because of the homogeneously distributed dislocations and the occurrence of cross-slip. During fatigue deformation, the interaction between the dislocation-dislocation or mobile dislocation and the precipitation phase results in hardening [14].

For near $\beta$ titanium alloys, different heat treatment processes often result in obviously different $\alpha / \beta$ morphology [15-17]. However, little information is available on the intrinsic connection between the cyclic deformation behavior and the transition of precipitation phases. In addition, it should be emphasized that the formation of $\alpha^{\prime \prime}$ is often induced during fatigue deformation [18,19]. Additionally, for titanium alloys, twinning has great effect on maintaining the homogeneous plastic deformation [20-24]. Therefore, it is necessary to study the effect of $\alpha^{\prime \prime}$ and twins on cyclic stress response behavior.

\section{Materials and Methods}

A $300 \mathrm{~mm}$ diameter ingot of the Ti-3Al-8V-6Cr-4Mo-4Zr alloy was produced by vacuum arc melting using pure Ti, $\mathrm{V}-\mathrm{Al}$ alloy, $\mathrm{Cr}, \mathrm{Zr}$ and Mo as raw materials. The ingot was forged at $850{ }^{\circ} \mathrm{C}$ to $55 \mathrm{~mm}$ diameter cylindrical bars, and then hot rolled at $800^{\circ} \mathrm{C}$ to $16 \mathrm{~mm}$ in diameter rods. The chemical compositions results are given in Table 1. According to the previous studies [25], after solution treated at $800{ }^{\circ} \mathrm{C}$ for $0.5 \mathrm{~h}(\mathrm{AC})+$ aging at $500{ }^{\circ} \mathrm{C}$, the alloys have a good resistance/ductility combination. So, samples were heat treated at $800^{\circ} \mathrm{C}$ for $0.5 \mathrm{~h}$ and cooled in air. Then some of these specimens were aged at $500{ }^{\circ} \mathrm{C}$ for $4,8,12$ and $24 \mathrm{~h}$, respectively, and cooled in air.

Table 1. Chemical composition of alloys (wt.\%).

\begin{tabular}{ccccccc}
\hline Alloy & Al & V & Cr & Mo & Zr & Ti \\
\hline Ti-3Al-8V-6Cr-4Mo-4Zr & 2.9 & 7.8 & 6.1 & 3.9 & 4.0 & Bal. \\
\hline
\end{tabular}

Uniaxial tensile properties were tested at room temperature $\left(\sim 25^{\circ} \mathrm{C}\right)$ and atmosphere using a rectangular specimen with cross section $2.0 \mathrm{~mm} \times 3.0 \mathrm{~mm}$ and a gage length $13 \mathrm{~mm}$. The LCF specimens with a gage length $20 \mathrm{~mm}$ and diameter $5 \mathrm{~mm}$ were processed, ground and polished. The LCF tests under total strain controlled were conducted at room temperature $\left(\sim 25^{\circ} \mathrm{C}\right)$ and atmosphere using an MTS landmark 370.10 servohydraulic test system (MTS, Eden Prairie, Minnesota, USA) with the strain ratios $(\mathrm{R})$ of -1 and a frequency of $0.5 \mathrm{~Hz}$.

The TEM slices were mechanically thinned down to a thickness of approximately $50 \mu \mathrm{m}$. Discs of $3 \mathrm{~mm}$ in diameter were punched out of the thin sheets and electro-polished with $60 \mathrm{~mL}$ perchloric acid, $85 \mathrm{~mL}$ n-butanol and $150 \mathrm{~mL}$ methanol at temperature $-33^{\circ} \mathrm{C}$. Microstructural observations were conducted with SEM (Zeiss Gemini 500, Heidenheim, Germany) and TEM (JEOL JEM-2100, Tokyo, Japan).

\section{Results}

\subsection{Microstructure before Fatigue Deformation}

Figure 1 shows TEM microstructure of the alloy with three different heat treatment processes. It can be found that $\alpha$ phase was precipitated from $\beta$ grains after heat treatment. With increasing the ageing time, the quantity of $\alpha$ phase decreased (volume fraction), but the size increased gradually. Moreover, the distance between $\alpha$ phase was also increasing. 

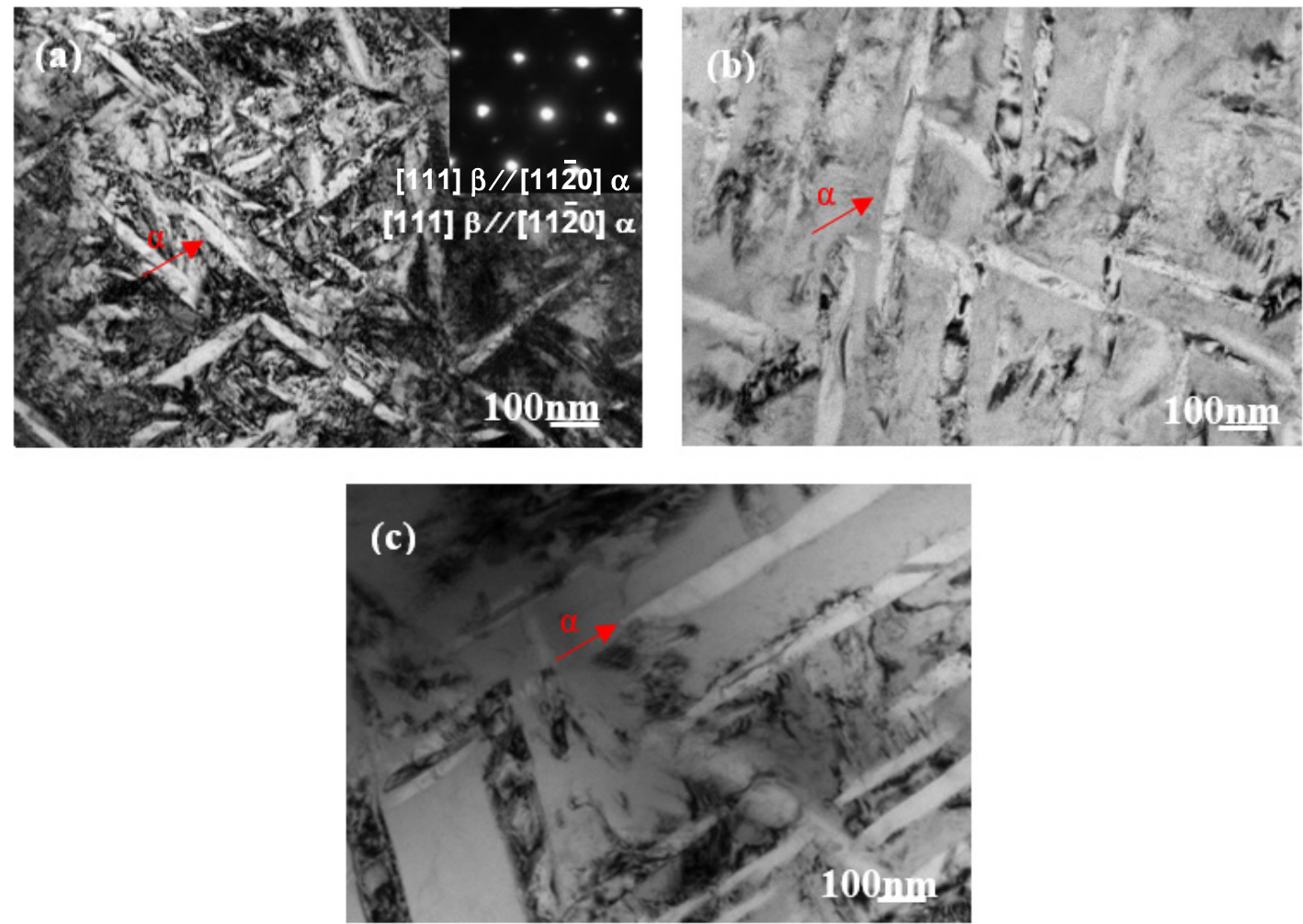

Figure 1. Microstructures of the alloy in different heat treatment conditions, (a) $800{ }^{\circ} \mathrm{C} / 30 \mathrm{~min}+$ $500{ }^{\circ} \mathrm{C} / 4 \mathrm{~h} \mathrm{(b)} 800{ }^{\circ} \mathrm{C} / 30 \mathrm{~min}+500{ }^{\circ} \mathrm{C} / 12 \mathrm{~h}(\mathbf{c}) 800{ }^{\circ} \mathrm{C} / 30 \mathrm{~min}+500{ }^{\circ} \mathrm{C} / 24 \mathrm{~h}$.

\subsection{Tensile Properties}

The mechanical properties of the alloy with different heat treatment microstructures were evaluated first by tensile tests, and the results are shown in Table 2. As the aging time increased, both the ultimate tensile strength $\left(\sigma_{\mathrm{b}}\right)$ and yield strength $\left(\sigma_{0.2}\right)$ increased significantly and then decreased rapidly, but the ductility almost stayed the same. Therefore, we can confirm that the alloy possessed the best tensile property after $12 \mathrm{~h}$ aging.

Table 2. Tensile properties of the alloy at room temperature.

\begin{tabular}{ccccc}
\hline Heat Treatment States & $\boldsymbol{\sigma}_{\mathbf{b}} / \mathbf{M P a}$ & $\boldsymbol{\sigma}_{0.2} / \mathbf{M P a}$ & $\begin{array}{c}\boldsymbol{\varphi} \text { (Elongation at Maximum } \\
\text { Tensile Strength) }\end{array}$ & $\boldsymbol{\psi}$ (Reduction of Area) \\
\hline $800^{\circ} \mathrm{C} / 30 \mathrm{~min}+500^{\circ} \mathrm{C} / 4 \mathrm{~h}$ & 1205.2 & 1137.8 & $12.98 \%$ & $16.94 \%$ \\
$800^{\circ} \mathrm{C} / 30 \mathrm{~min}+500^{\circ} \mathrm{C} / 12 \mathrm{~h}$ & 1452.1 & 1436.9 & $12.75 \%$ & $15.85 \%$ \\
$800{ }^{\circ} \mathrm{C} / 30 \mathrm{~min}+500{ }^{\circ} \mathrm{C} / 24 \mathrm{~h}$ & 1115.6 & 1088.6 & $12.67 \%$ & $15.18 \%$ \\
\hline
\end{tabular}

\subsection{Strain Amplitude in Fatigue}

It can be seen from Figure 2 that the three curves (total, elastic and plastic strains) are linear on $\log -\log$ scale. There is an intersection of elastic and plastic strain-life curves, called as the transition fatigue life $2 \mathrm{Nt}$, the life at which elastic and plastic regions of strain are equal. For the alloy after aging, at the lower cycle region when $2 \mathrm{Nf} \leq 2 \mathrm{Nt}$, the plastic strain plays a main role and fatigue properties are dominated by strength, while at the higher cycle region when $2 \mathrm{Nf} \geq 2 \mathrm{Nt}$, the elastic strain plays a main role and fatigue properties are dominated by ductility. 

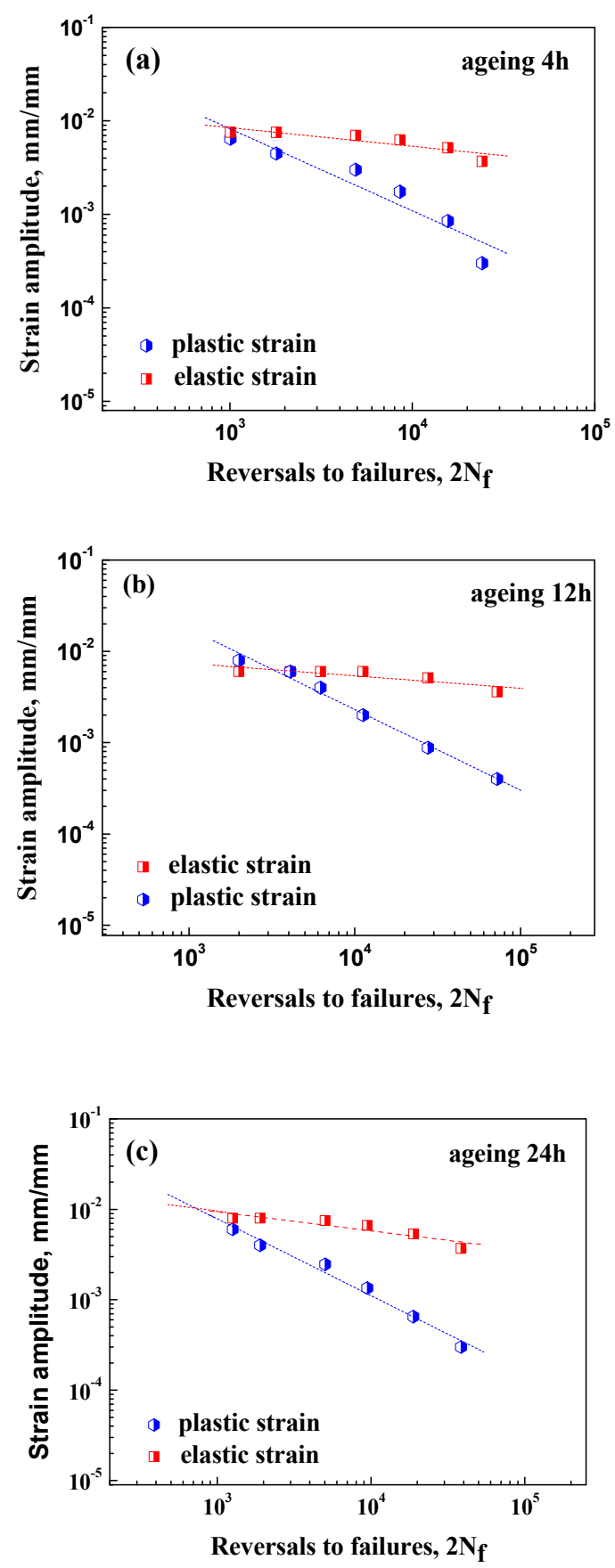

Figure 2. Strain amplitude versus reversals to failure curves for Ti-3Al-8V-6Cr-4Mo-4Zr alloys in different state. (a) Aging after $4 \mathrm{~h}$, (b) aging after $12 \mathrm{~h}$, (c) aging after $24 \mathrm{~h}$.

\subsection{Cyclic Stress Response Behaviour}

Strain-controlled low cycle fatigue behaviors of the alloys with different heat treatment microstructures were studied at $\mathrm{R}=-1$ and the frequency of $0.5 \mathrm{~Hz}$ at room temperature and atmosphere. The cyclic stress response curves of alloy with different aging times are showed in Figure 3 . It can be found that fatigue life for each alloy decreased as the strain amplitude increases. The cyclic stress response behavior was highly dependent on aging time and strain amplitude. 


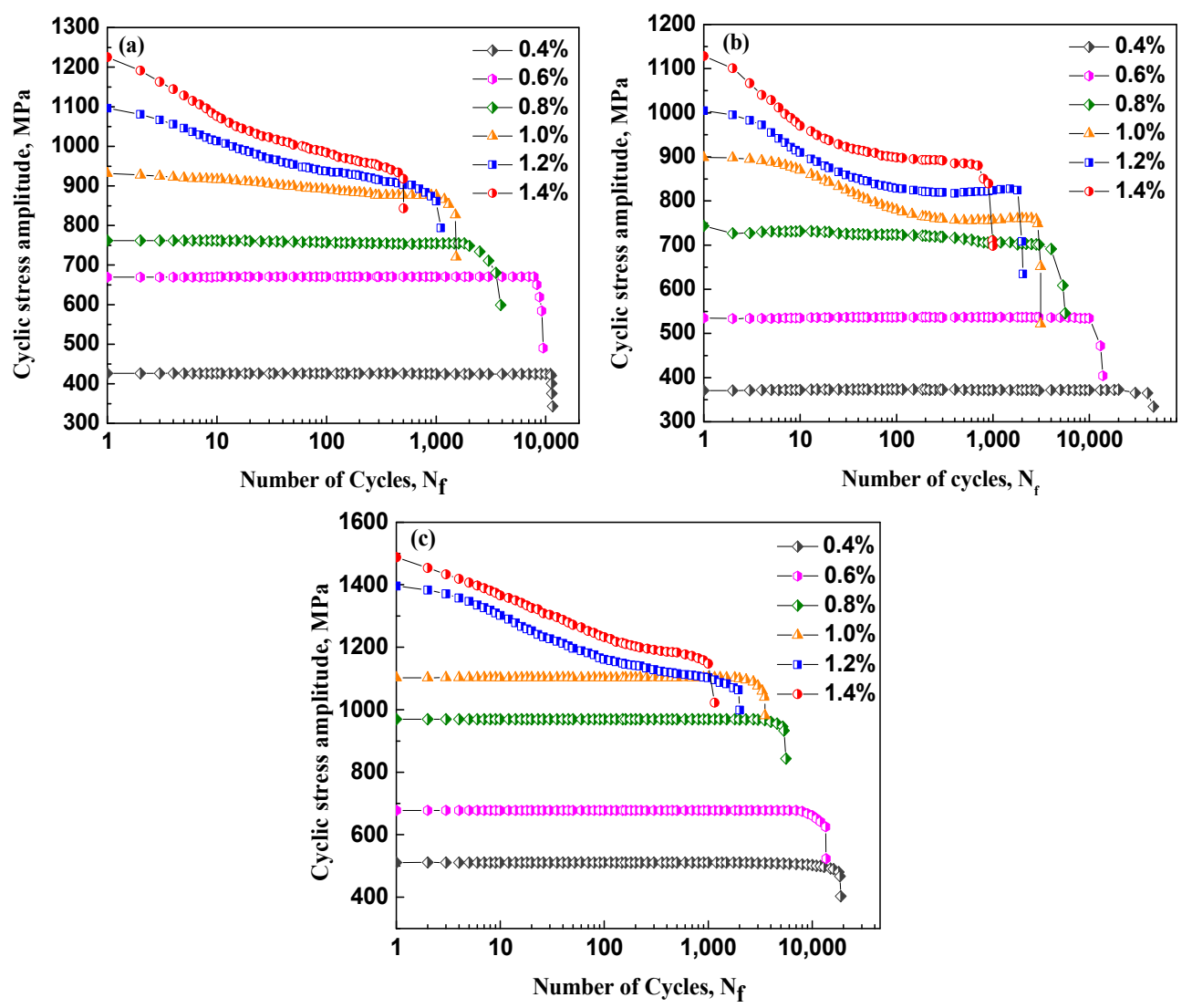

Figure 3. Cyclic stress response curves of the alloy after aging treatment. (a) $4 \mathrm{~h}$, (b) $12 \mathrm{~h}$ (c) $24 \mathrm{~h}$.

(a) At low total strain amplitude (alloys aging for $4 \mathrm{~h}$ and $24 \mathrm{~h}$ : $\Delta \varepsilon / 2 \leq 1.0 \%$, alloy aging for $12 \mathrm{~h}$ : $\Delta \varepsilon / 2 \leq 0.8 \%$ ), cyclic saturation was exhibited, followed by a short stage of softening.

(b) At high total strain amplitude (alloys aging for $4 \mathrm{~h}$ and $24 \mathrm{~h}: \Delta \varepsilon / 2>1.0 \%$, alloy aging for $12 \mathrm{~h}$ : $\Delta \varepsilon / 2>0.8 \%$ ), the alloy generally exhibited a rapid cyclic softening. It is worth mentioning that, for the alloy aging for $12 \mathrm{~h}$ at $\Delta \varepsilon / 2 \geq 1.0 \%$, cyclic saturation stage after the initial softening was reached and extended through the last part of the fatigue life.

\subsection{Microstructure after Fatigue Deformation}

Microstructures corresponding to the different heat treatment alloy after the low cycle fatigue (LCF) were characterized by TEM analysis. Figure 4 is a TEM microstructure of alloy after LCF under $0.4 \%$ total strain amplitude. From the picture, it can be noticed that the dislocation density increased obviously after LCF deformation, compared to heat treatment microstructure. Figure 5 shows the TEM microstructure of alloy after LCF under $1.4 \%$ total strain amplitude. Compared with the microstructure under $0.4 \%$ total strain amplitude, the dislocation density increased further, especially for alloy aging for $4 \mathrm{~h}$ (Figure 5a). In addition, through a lower magnification overview of the microstructure (Figure $5 \mathrm{~b}$ ), it can be also found that the alloy aging for $12 \mathrm{~h}$ consists of nano-size twins which were locally distributed. The selected-area taken from the red circle region marked in Figure $5 b$ is presented in Figure $5 c$, from which we can determined that the $\sim 5 \mathrm{~nm}$ twin plate is a typical $\{332\}<113>$ twin pattern. Interestingly, some extra reflections which can be inferred as the $\alpha^{\prime \prime}$ martensite structure were also visible (Figure $5 \mathrm{~d}$ ), in addition to the formation of $\{332\}<113>$ twin. It can be seen that the stress induced the formation of $\alpha^{\prime \prime}$ martensite is located on the one side of the twin boundary. Moreover, a detwinning process also took place after LCF (Figure 5e). Some parts of the twins decreased obviously as the size of $\alpha^{\prime \prime}$ martensite was increased. Interestingly, the twins might transform back into the matrix, thus significantly decreasing the area of the twin interface i.e., decreasing of the total interfacial energy, which might be the driving force of the process of detwinning. The $\{332\}<113>$ twins partly 
transformed into the matrix and the $\alpha^{\prime \prime}$ martensite at the shared interface took place of the detwinning area (Figure 5e). These observations indicated that the formation of stress induced $\alpha^{\prime \prime}$ martensite might have undergone a complex process, and the nature of the phenomenon needs to be investigated deeply later. As to the alloy aging for $4 \mathrm{~h}$ and $24 \mathrm{~h}$ under $1.4 \%$ total strain amplitude, With the increase of dislocation density, it is easy to produce multi-system slip and reduce the effective stress, thus showing the trend of cyclic softening(Figure 5a,f).
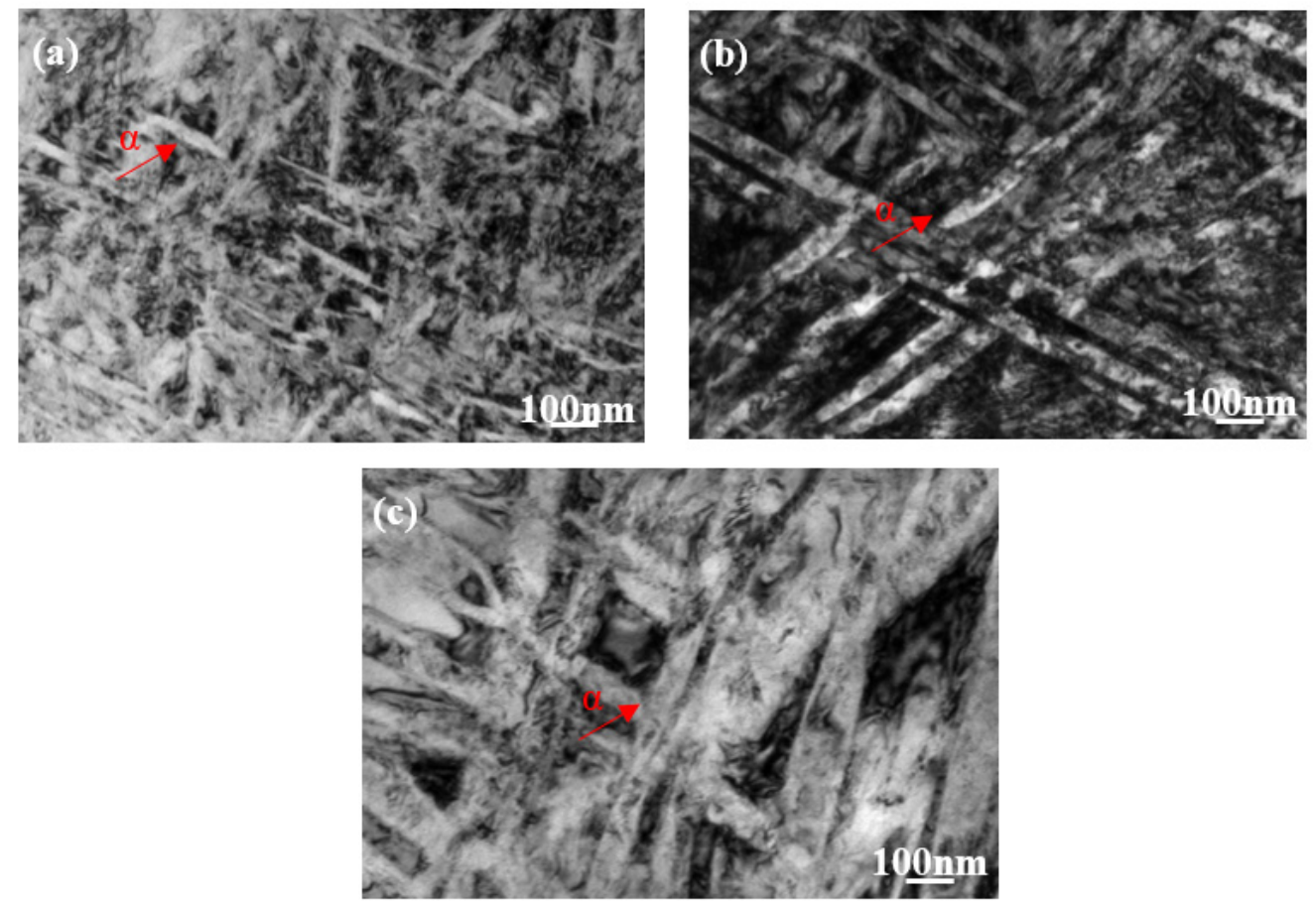

Figure 4. TEM images of the alloys with different aging treatment after fatigue tests under $0.4 \%$ total strain range. (a) $4 \mathrm{~h}$, (b) $12 \mathrm{~h}$ and (c) $24 \mathrm{~h}$.
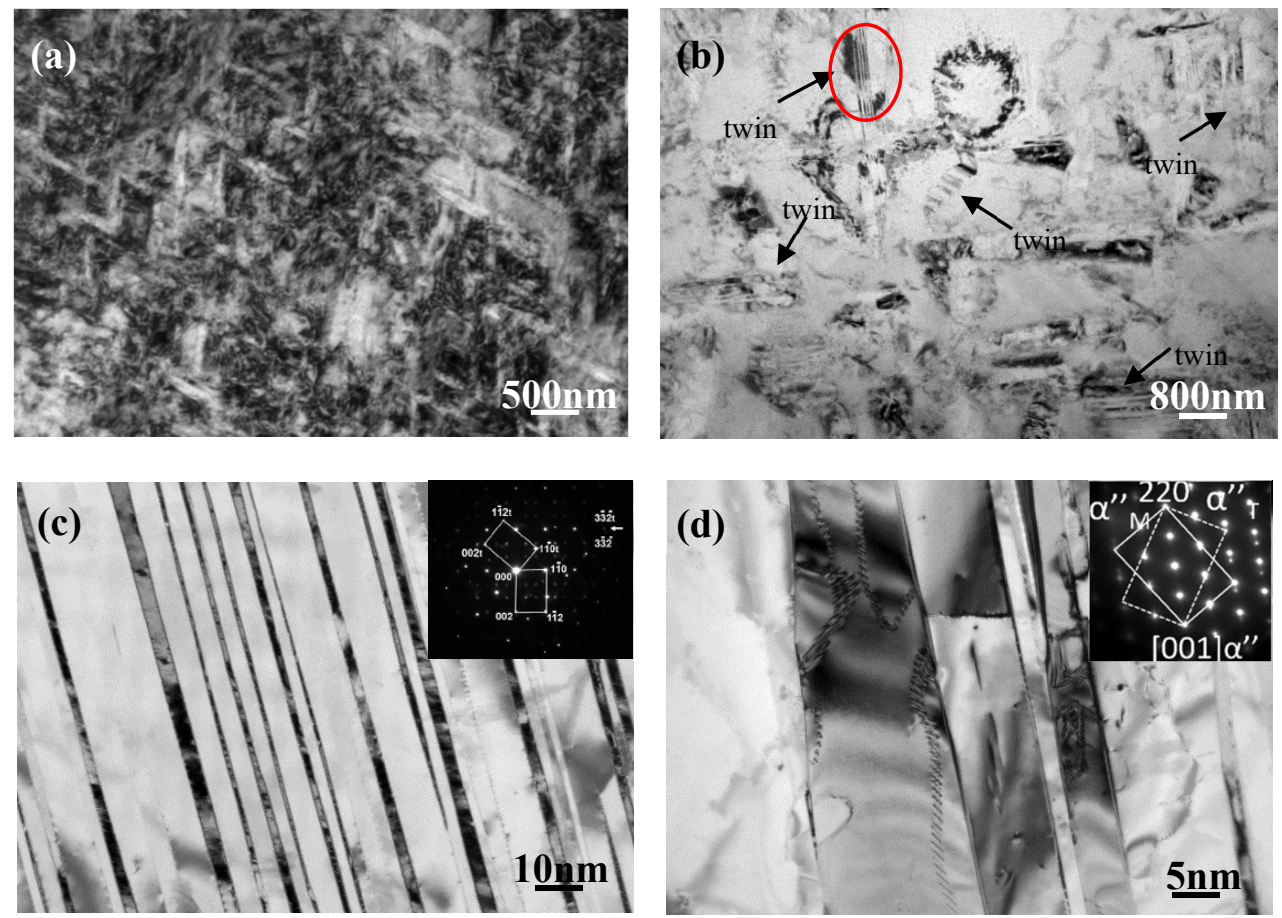

Figure 5. Cont. 

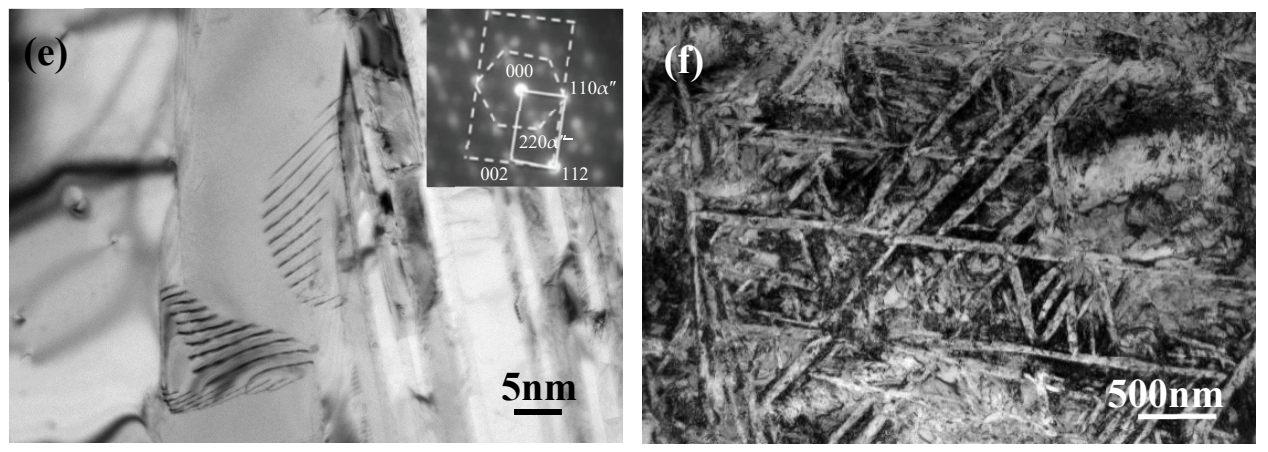

Figure 5. TEM images of the alloys with different aging treatment after fatigue tests under $1.4 \%$ total strain range. (a) $4 \mathrm{~h},(\mathbf{b}-\mathbf{e}) 12 \mathrm{~h}$ and (f) $24 \mathrm{~h}$.

\section{Discussion}

According to the above results, we can infer that the cyclic stress response behavior of near $\beta$ titanium alloy was highly dependent on the applied plastic strain amplitude and precipitated phase.

At low strain amplitude, an apparently cyclic saturation stage was exhibited until fracture for all three alloys. It appeared that the plastic deformation was restricted to the soft $\alpha$ phase, with the hard $\beta$-phase staying in its elastic domain. Therefore, it can be considered that the dislocations movement in matrix was negligible due to the large quantity of $\alpha / \beta$ interfaces which hinder gliding. It is interesting, for alloys aged for $24 \mathrm{~h}$ possess a perfect cyclic stability up to a total strain amplitude of $\Delta \varepsilon / 2=1.0 \%$ and stress amplitude up to $1100 \mathrm{MPa}$. It could be because the distance between $\alpha$ phase was relatively large, and $\alpha^{\prime \prime}$ martensite and twins were not easily precipitated for alloys aged for $24 \mathrm{~h}$.

At high strain amplitude, three alloys all displayed an initial striking cyclic softening. However, the softening mechanism may be obviously different. For alloys aging for $4 \mathrm{~h}$ and $24 \mathrm{~h}$, the softening behavior was closely related to mobile dislocation. It was well known that prismatic slip could be activated at high cyclic strain amplitude. The continuous softening was controlled by the gradual homogenization of the initially heterogeneous distribution of the dislocations in the $\alpha$ phase in association with cross-slip. The cross-slip activation at room temperature may be related to the presence of additional elements in the $\alpha$ phase and to a high stacking fault energy associated with the prismatic slip [11]. In addition, for alloys aging for $12 \mathrm{~h}$, the formation of the twin due to strain incompatibility might also have effect on the initial softening response of the samples during cycling. It was noticed that the microstructure evolution and cyclic stress response were connected with the $\{332\}<113>$ twins in this study. As the twins formed and grew, the trend of the cyclic stress curve, shown in Figure 4, might be well explained by softening the mechanism in terms of a crystallographic orientation of a deforming crystal structure. Earlier reports indicated that deformation twinning can induce the structural softening in a twinned region, since texture evolution was associated with the lattice reorientation [26]. TEM studies have indicated that slip precedes twin formation [27].

Interestingly, for alloy aging for $12 \mathrm{~h}$, a significantly cyclic saturation stage was noticed after an initial cyclic softening. This would imply that there was a balance between the counteracting effects of the softening and hardening mechanism. According to the TEM microstructure, we can infer that the precipitation of $\alpha^{\prime \prime}$ martensite was the main reason for the hardening. As the cycling proceeds, the formation of $\alpha^{\prime \prime}$ pined the dislocations and further increased the stress. It can be said that the irregular twin boundary assists the transformation of $\alpha^{\prime \prime}$ martensite through lattice reorientation [28,29]. From Figure 4, it can be found that some of the twins partly transformed into the matrix and $\alpha^{\prime \prime}$ martensite at the shared interface took the place of the detwinning area due to the decrease in strain energy. During the LCF process, the residual stress near the twin region might be partially released and the lattice strain around the twin would gradually relax. Furthermore, the twins make opposite contributions to the macroscopic strains. As deformation progresses, the stress can be released by local compatible deformation. Under an external applied stress, a crystal with a twinned part has to make a 
positive contribution with respect to the macroscopic strain field to be compatible with its surroundings, which gives rise to the occurrence of detwinning [30]. Then, the SIM at the Shared interface took place of the detwinning area. The cyclic saturation stress in the alloy aging for $12 \mathrm{~h}(\Delta \varepsilon / 2>0.8 \%)$ which associates with the increased strain hardening caused by SIM can be clarified by dynamic Hall-Petch theory [31]. The formation of $\alpha^{\prime \prime}$ martensite rather adjoined with the twin boundaries obviously decreased the effective dislocation glide distance, and $\beta$ grains could be segmented into smaller zones by the deformation of the SIM phase and the phase boundaries acted as impenetrable barriers for the dislocation glide [32]. Figure 4 shows that many dislocations slip into $\alpha^{\prime \prime}$ martensite and form an immovable dislocation array, and the movable dislocation decreases with the cyclic stress, which provides support for the enhanced strain hardening, and the cooperation between $\alpha^{\prime \prime}$ martensite and twins causes the formation of cyclic stress stability.

\section{Conclusions}

In the present work, the cyclic stress response behavior of Ti-3Al-8V-6Cr-4Mo-4Zr alloy with three different microstructures has been studied. The following main conclusions can be drawn in this work:

(1) The alloy aging for $12 \mathrm{~h}$ possessed the optimal $\alpha / \beta$ morphology and exhibited the best tensile and LCF properties.

(2) At low strain amplitude, an obvious cyclic saturation stage was revealed until fracture for all three alloys.

(3) At high strain amplitude, three alloys all displayed an initial striking cyclic softening. However, for alloy aging for $12 \mathrm{~h}$, a cyclic saturation stage was obtained after an initial cyclic softening.

(4) The deformation of $\{332\}<113>$ twin and precipitation of $\alpha$ " martensite were found to have a crucial influence on the cyclic stress response behavior.

Author Contributions: Contributed materials and performed the experiments, J.L., H.Z., J.H. and L.C.; designed the experiments, J.S.; analyzed the data and wrote the paper, S.Z. All authors have read and agreed to the published version of the manuscript.

Funding: This research was funded by Liaoning provincial Natural Science Foundation projects (20180550998), National Natural Science Foundation of China (51501117) and (52071219), and Foundation of state key laboratory of rolling and automation, northeastern university (2018RALKFKT010).

Conflicts of Interest: The authors declare no conflict of interest.

\section{References}

1. Koizumi, H.; Takeuchi, Y.; Imai, H.; Kawai, T.; Yoneyama, T. Application of titanium and titanium alloys to fixed dental prostheses. J. Prosthodont. Res. 2019, 63, 266-270. [CrossRef] [PubMed]

2. Hong, S.H.; Hwang, Y.J.; Park, S.W.; Park, C.H.; Yeom, J.-T.; Park, J.M.; Kim, K. Low-cost beta titanium cast alloys with good tensile properties developed with addition of commercial material. J. Alloys Compd. 2019, 793, 271-276. [CrossRef]

3. Bin Asim, U.; Siddiq, A.; Kartal, M.E. A CPFEM based study to understand the void growth in high strength dual-phase titanium alloy (Ti-10V-2Fe-3Al). Int. J. Plast. 2019, 122, 188-211. [CrossRef]

4. Srivatsan, T.; Soboyejo, W.; Lederich, R. The cyclic fatigue and fracture behavior of a titanium alloy metal matrix composite. Eng. Fract. Mech. 1995, 52, 467-491. [CrossRef]

5. Grosdidier, T.; Combress, Y.; Gautier, E.; Philippe, M.J. Effect of microstructure variations on the formation of deformation-induced martensite and associated tensile properties in a b metastable Ti alloy. Metall. Mater. Trans. A 2000, 31A, 1095-1106. [CrossRef]

6. Hua, K.; Zhang, Y.; Gan, W.; Kou, H.; Beausir, B.; Li, J.; Esling, C. Hot deformation behavior originated from dislocation activity and $\beta$ to $\alpha$ phase transformation in a metastable $\beta$ titanium alloy. Int. J. Plast. 2019, 119, 200-214. [CrossRef]

7. Sun, Q.Y.; Song, S.J.; Zhu, R.H.; Gu, H.C. Toughening of titanium alloys by twinning and martensite transformation. J. Mater. Sci. 2002, 37, 2543-2547. [CrossRef] 
8. Gouthama, N.S.; Singh, V. Low cycle fatigue behaviour of Ti alloy Timetal 834 at $873 \mathrm{~K}$. Int. J. Fatigue 2007, 29, 843-851. [CrossRef]

9. Zhang, Y.; Chen, Z.; Qu, S.J.; Feng, A.; Mi, G.; Shen, J.; Huang, X.; Chen, D. Microstructure and cyclic deformation behavior of a 3D-printed Ti-6Al-4V alloy. J. Alloys Compd. 2020, 825, 153971. [CrossRef]

10. Ibrahim, A.M.H.; Balog, M.; Krizik, P.; Novy, F.; Cetin, Y.; Svec, P.; Bajana, O.; Drienovsky, M. Partially biodegradable Ti-based composites for biomedical applications subjected to intense and cyclic loading. J. Alloys Compd. 2020, 839, 155663. [CrossRef]

11. Luquiau, D.; Feaugas, X.; Clavel, M. Cyclic softenimg of the Ti-10V-2Fe-3Al titanium alloy. Mater. Sci. Eng. A. 1997, 224, 146-156. [CrossRef]

12. Cottrell, A.H. Dislocations and Plastic Flow in Crystals; Oxford University Press: Oxford, London, 1953.

13. Béranger, A.; Feaugas, X.; Clavel, M. Low cycle fatigue behavior of an $\alpha+\beta$ titanium alloy: Ti6246. Mater. Sci. Eng. A 1993, 172, 31-41. [CrossRef]

14. Giugliano, D.; Cho, N.-K.; Chen, H.; Gentile, L. Cyclic plasticity and creep-cyclic plasticity behaviours of the $\mathrm{SiC} / \mathrm{Ti}-6242$ particulate reinforced titanium matrix composites under thermo-mechanical loadings. Compos. Struct. 2019, 218, 204-216. [CrossRef]

15. Santos, P.F.; Niinomi, M.; Cho, K.; Liu, H.; Nakai, M.; Narushima, T.; Ueda, K.; Itoh, Y. Effects of Mo Addition on the Mechanical Properties and Microstructures of Ti-Mn Alloys Fabricated by Metal Injection Molding for Biomedical Applications. Mater. Trans. 2017, 58, 271-279. [CrossRef]

16. Du, Z.; Ma, Y.; Liu, F.; Zhao, X.; Chen, Y.; Li, G.; Liu, G.; Chen, Y. Improving mechanical properties of near beta titanium alloy by high-low duplex aging. Mater. Sci. Eng. A 2019, 754, 702-707. [CrossRef]

17. Bertrand, E.; Castany, P.; Péron, I.; Gloriant, T. Twinning system selection in a metastable $\beta$-titanium alloy by Schmid factor analysis. Scr. Mater. 2011, 64, 1110-1113. [CrossRef]

18. Lee, B.-S.; Im, Y.-D.; Kim, H.G.; Kim, K.; Kim, W.-Y.; Lim, S.-H. Stress-Induced $\alpha$ " Martensitic Transformation Mechanism in Deformation Twinning of Metastable $\beta$-Type Ti-27Nb-0.5Ge Alloy under Tension. Mater. Trans. 2016, 57, 1868-1871. [CrossRef]

19. Blackburn, M.J.; Feeny, J.A. Stress-induced transformations in Ti-Mo alloys. J. Inst. Met. 1971, 99, $132-134$.

20. Lai, M.J.; Tasan, C.C.; Raabe, D. On the mechanism of $\{332\}$ twinning in metastable $\beta$ titanium alloys. Acta Mater. 2016, 111, 173-186. [CrossRef]

21. Gao, Y.; Zheng, Y.; Fraser, H.; Wang, Y. Intrinsic coupling between twinning plasticity and transformation plasticity in metastable $\beta$ Ti-alloys: A symmetry and pathway analysis. Acta Mater. 2020, 196, 488-504. [CrossRef]

22. Gong, M.Y.; Xu, S.; Capolungo, L.; Tomé, C.N.; Wang, J. Interactions between <a>dislocations and three-dimensional \{1122\} twin in Ti. Acta Mater. 2020, 195, 597-610. [CrossRef]

23. Chen, N.; Aldareguia, J.M.M.; Kou, H.C.; Qiang, F.M.; Wu, Z.H.; Li, J.S. Reversion martensitic phase transformation induced $\left\{\begin{array}{lll}3 & 3 & 2\end{array}\right\}<13>$ twinning in metastable $\beta$-Ti alloys. Mater. Lett. 2020, 272, 127883. [CrossRef]

24. Ren, L.; Xiao, W.; Kent, D.; Wan, M.; Ma, C.; Zhou, L. Simultaneously enhanced strength and ductility in a metastable $\beta$-Ti alloy by stress-induced hierarchical twin structure. Scr. Mater. 2020, 184, 6-11. [CrossRef]

25. Cao, S.; Zhou, X.; Lim, C.V.S.; Boyer, R.R.; Williams, J.C.; Wu, X. A strong and ductile Ti-3Al-8V-6Cr-4Mo-4Zr (Beta-C) alloy achieved by introducing trace carbon addition and cold work. Scr. Mater. 2020, 178, 124-128. [CrossRef]

26. Shin, S.; Zhu, C.Y.; Vecchio, K.S. Observations on $\{332\}<113>$ twinning- induced softening in Ti-Nb Gum Metal. Mater. Sci. Eng. A. 2018, 724, 189-198. [CrossRef]

27. De Cooman, B.C.; Estrin, Y.; Kim, S.K. Twinning-induced plasticity (TWIP) steels. Acta Mater. 2018, 142, $283-362$. [CrossRef]

28. Chen, B.; Sun, W. Transitional structure of $\{332\}<113>\beta$ twin boundary in a deformed metastable $\beta$-type Ti-Nb-based alloy, revealed by atomic resolution electron microscopy. Scr. Mater. 2018, 150, 115-119. [CrossRef]

29. Castany, P.; Yang, Y.; Bertrand, E.; Gloriant, T. Reversion of a parent $\{130\}<310>\alpha$ " martensitic Twinning system at the origin of $\{332\}<113>\beta$ twins observed in metastable $\beta$ titanium alloys. Phys. Rev. Lett. 2016, 117, 245501. [CrossRef] [PubMed]

30. Qu, L.; Yang, Y.; Lu, Y.F.; Feng, L.; Ju, J.H.; Ge, P.; Zhou, W.; Han, D.; Ping, D.H. A detwinning process of $\{332\}<113>$ twins in beta titanium alloys. Scr. Mater. 2013, 69, 389-392. [CrossRef] 
31. Idrissi, H.; Renard, K.; Schryvers, D.; Jacques, P. On the relationship between the twin internal structure and the work-hardening rate of TWIP steels. Scr. Mater. 2010, 63, 961-964. [CrossRef]

32. Cho, K.; Morioka, R.; Harjo, S.; Kawasaki, T.; Yasuda, H.Y. Study on formation mechanism of $\{332\}<113>$ deformation twinning in metastable $\beta$-type Ti alloy focusing on stress-induced $\alpha$ " martensite phase. Scr. Mater. 2020, 177, 106-111. [CrossRef]

Publisher's Note: MDPI stays neutral with regard to jurisdictional claims in published maps and institutional affiliations.

(C) 2020 by the authors. Licensee MDPI, Basel, Switzerland. This article is an open access article distributed under the terms and conditions of the Creative Commons Attribution (CC BY) license (http://creativecommons.org/licenses/by/4.0/). 